were seen in two and three cases respectively. Ultrastructural examination showed electron-dense deposits localised in the mesangium in nine cases.

Patients were treated during the first month with prednisone $1 \mathrm{mg} / \mathrm{kg}$ per day. During the next two months the dose was reduced to $1 \mathrm{mg} / \mathrm{kg}$ on alternate days and then gradually decreased. Steroid-resistant patients were treated with $0.2 \mathrm{mg} / \mathrm{kg}$ per day of chlorambucil for three months. In no case was the total dose of chlorambucil greater than $25 \mathrm{mg} / \mathrm{kg}$. One nephrotic patient experienced spontaneous remission and eight others were steroidresponsive. Only one of the five steroidresistant patients treated with chlorambucil showed clinical remission. Five steroidresponsive patients relapsed. At present, four patients are "healthy," having not relapsed for the past two years.

We think it is important to determine if the presence of IgM in renal biopsies indicates a poor prognosis in idiopathic nephrotic syndrome. Cohen et al. ${ }^{1}$ have suggested a relatively poor prognosis in five such patients after treatment, showing clinical remission in only one case. On the other hand, Bhasin et al. ${ }^{2}$ described six of eight patients who initially achieved clinical remission, although four of these later required cytotoxic drugs or were steroid-dependent. It therefore appears that whereas the short-term prognosis in IgM associated mesangial proliferative glomerulonephritis is good, the longterm outlook must be much more guarded. ${ }^{3}$

We do not know whether IgM mesangial nephropathy is really a single disease entity or whether the IgM deposition is simply a concomitant immunological finding not necessarily related to the pathogenesis of the nephrotic syndrome." Only a small number of cases have been reported of this ill-defined glomerular disease. A definitive statement regarding the course and prognosis is not possible. More studies are necessary to confirm that IgM mesangial nephropathy is indeed a separate entity.

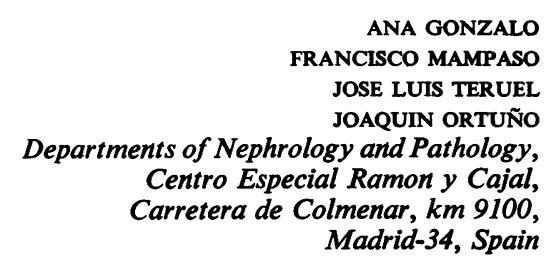

References

1 Cohen AH, Border WA, Glassock RJ. Nephrotic syndrome with glomerular mesangial IgM deposits. Lab Invest 1978;38:610-9.

a Bhasin HK, Abuelo JG, Nayak T, Esparza AR. Mesangial proliferative glomerulonephritis. Lab Invest 1978;39:21-9.

${ }^{3}$ Lawler W, Williams G, Tarpey P, Mallick NP. IgM associated primary diffuse mesangial proliferative glomerulonephritis. J Clin Pathol 1980;33:1029-38.

- Case Records of the Massachusetts General Hospital (Case 32-1980). N Engl J Med 1980;303:382-9.

Dr Lawler and his colleagues comment as follows:

Thank you for inviting us to comment on the letter by Gonzalo et al. The cases which they describe appear to be very similar to ours ${ }^{1}$ in structural and immunopathological terms, although criteria for selection were different; thus all their 14 patients had the nephrotic syndrome, whereas 9 of our 23 patients ${ }^{1}$ had asymptomatic proteinuria.

In our experience, based on these 23 cases $^{1}$ and another unpublished group of 20 similar cases of IgM-associated primary diffuse mesangial proliferative glomerulonephritis, both clinical remission during steroid therapy and spontaneous improvement are uncommon, the majority of patients pursuing a chronic indolent course which, in a minority, progresses to end-stage renal failure. It may well be that what we and others, ${ }^{23}$ including Gonzalo et al., have described is a heterogeneous group, and that the patients who improve, either spontaneously or with steroid therapy, may represent a different pathogenetic mechanism. Nevertheless, the fact that the majority do not improve suggests that they should be considered as a distinct clinicopathological group.

We agree that further long-term studies are required to confirm IgM mesangial nephropathy as a separate entity and, if so, to determine its course and ultimate prognosis.
W LAWLER G WILLIAMS NP MALLICK Department of Pathology, Stopford Building, Oxford Road, Manchester M13 9PT
References

${ }^{1}$ Lawler W, Williams G, Tarpey P, Mallick NP. IgM associated primary diffuse mesangial proliferative glomerulonephritis. J Clin Pathol 1980;33:1029-38.

2 Cohen AH, Border WA, Glassock RJ. Nephrotic syndrome with glomerular mesangial IgM deposits. Lab Invest 1978;38:610-9.

3 Bhasin HK, Abuelo JG, Nayak T, Esparza AR. Mesangial proliferative glomerulonephritis. Lab Invest 1978;39:21-9.

\section{Misapplication of Russell's name}

The paper by Bartolini et al. (October $1980 ; 33: 936)$ contains clerical slips in the spelling: Russel's bodies, but a more serious error in suggesting that the intracellular bodies described by Russell $(1890)^{1}$ occur within plasma cells. Russell stated that these fuchsinophil bodies occurred within and around cancer cells, but not in sarcomata or in simple tumours.

Modern staining methods make it fairly certain that the inclusions seen in carcinoma cells are of fibrin, and this gains support by the greater number of inclusions within carcinoma cells adjacent to fibrinous coagula. On the other hand, the inclusions within plasma cells are now linked to immunological changes, do not stain exactly as fibrin, and surely should never be called Russell bodies.

AC LENDRUM Royal Infirmary, Dundee DD1 9ND

\section{Reference}

${ }^{1}$ Russell W. An address on a characteristic organism of cancer. $\mathrm{Br}$ Med J 1890;ii: 1297 and 1356-60.

\section{Ethanol-induced vacuolation in red cells}

The article "Cytoplasmic vacuolation of peripheral blood cells in acute alcoholism" (J Clin Pathol 1980;33:1193-6) found our interest. Working in the field of haemorheology, we carry out studies of red cell deformability (RCD) using a filtration method based on a technique originally developed in our laboratory and described in this Journal. ${ }^{2}$ Studying healthy volunteers, we observed that RCD was reduced after alcohol intake during the night before the measurement (on average $13 \%$ ). Subsequently we performed a series of in vitro experiments, determining the RCD of physiologically deformable red 
cells before and after incubation with ethanol (concentration 2 and 20\%; incubation time 1 hour; temperature $\left.37^{\circ} \mathrm{C}\right)$. We found an average reduction in RCD of 6 and $14 \%$ respectively.

These preliminary results suggest that changes in RCD might be induced by ethanol. Changes of red cell morphology are known to alter RCD. ${ }^{3}$ In this context the observation that ethanol causes vacuolation of white and red cells might be important. Although we did not observe gross changes in erythrocyte morphology by routine light microscopy in our experiments, such changes might still be present to a degree too minor to be detected by this method. Thus the findings reported in the above mentioned paper could give a clue as to how to explain our results. Further investigations are needed to study the problem.

\section{E ERNST \\ Department Medicine, St George's Hospital Medical School, London SWI7 ORE}

References

${ }^{1}$ Reid HL, Barnes AJ, Lock PJ, Dormandy JA, Dormandy TL. A simple method for measuring erythrocyte deformability. J Clin Pathol 1976;29:855-8들

${ }^{2}$ Dodds AJ, O'Reilly MJG, Yates CP, $e \bar{\Phi}_{a l}$. Haemorheological response to plaşna exchange in Raynaud's syndrome. $\mathrm{\nabla} B r$ Med J 1979; ii:1186-7.

${ }^{3}$ Weed RJ, Lacelle PL, Merrill Metabolic dependence of red cell deformability. J Clin Invest 1969,\$8: 795-809.

\section{Book reviews}

Practical Methods in Clinical Immunology Series. Vol 2. Immunological Investigation of Tropical Parasitic Diseases. V Houba. (Pp 170; £16.) Churchill Livingstone. 1980.

It is an opportune moment for this book as there is a resurgence of immunological interest in tropical diseases. It contains ten chapters, each of which deals with one or a collection of closely related tropical parasitic diseases. In each chapter there is a brief outline of the clinical and parasitological aspects of the disease, followed by a more extensive discussion of the immune response. Each concludes with a detailed appraisal of all the serological techniques which have been applied to that particular disease. The practical details of recommended techniques at the end of each chapter and the appendix are the most useful parts of the book. These are given in sufficient detail for the reader to be able to set them up in his own laboratory.

This book is a 'must' for any parasitological laboratory dealing with diagnosis or immunological research. A VOLLER

Endocrine Disorders A Pathophysiologic Approach. 2nd ed. Will G Ryan. (Pp xv + 148; illustrated; £13.) Year Book Medical Publishers. 1980.

This book is one of a series in Internal Medicine and is intended to be an introductory text for students. This second edition has not been extensively rewritten, a material update and the correction of minor errors being the main changes. It is concise and brief covering the main aspects of endocrinology and will be widely read by the student interested in this topic.
The stated normal values for various hormonal concentrations are sometimes different from those reported in Great Britain and values are not quoted. These are, however, minor criticisms. The book is aimed at the student and not at the established clinician or laboratory worker. It will be of great value to those struggling to gain some knowledge of the rapidly expanding field of endocrinology.

GW PENNINGTON

Alien Histocompatibility Antigens in Cancer. Eds MM Bortin and RL Truitt. (Pp 221; illustrated; \$29.50.) Grune \& Stratton. 1980.

This is the hardcover edition of the March 1980 issue of Transplantation Proceedings (Vol XII, No 1), which includes the material presented at a conference held in Racine, Wisc. in May 1979, together with discussion. The presence of alien, ie, 'not self' for the host, histocompatibility antigens on tumour cell has recently been studied in some detail, mainly for the $\mathrm{H}-2$ system of mice, where the presence of new H-2 specificities and/or loss of existing antigens has been demonstrated. This phenomenon has been suggested to arise from one of several mechanisms, including the presence of endogenous virus (a notorious hazard in mouse tumour serology, well illustrated here by data from Klein) alteration of $\mathrm{H}-2$ by endogenous virus or some other virus induced mechanism, or more intriguingly, from derepression of existing H-2 genes, normally suppressed by genetic regulatory factors. The papers in this volume present detailed evidence for the existence of these novel antigens, and the consensus is that these are not tumour specific trangplantation antigens (TSTA), althoughoin some chemically induced tumours, they-do behave as tumour antigens (TA). The ffral section deals with the potential explo $\mathrm{F}$ ation of these antigens as tools for diagnosis and even to manipulate immunotheras y. The field is new, potentially exciting, and although these papers are highly technical, they deserve attention. For immunologists with an interest in tumours andor transplants (which must mean more tha select few) this book is a must.The secold symposium due to be held in late 1980 may offer even better pickings.

HEATHER M D@̈

Renal Adenocarcinoma. UICC Techn䙔 Report Series Vol 49-A series of Woirkshops on the Biology of Human Caner. Report No 10. Ed G Sufrin and SA Beckley. (Pp 215; Sw fr 17.) UIGe, Geneva. 1980.

The workshop set out to assess currênt knowledge of, and to identify promis areas for future research into, renal adencarcinoma. Studies on model systems, biochemistry, immunology, cell kinetiç, epidemiology, histopathology, radiology, chemotherapy, and biochemical and clinical markers are reviewed in extenso a od critically analysed, and the result is a wơtk of reference likely to be of great practieal value to workers in many disciplines. part of the review devoted to future prôspects is much less well analysed giving impression that virtually any and eveoy line of research would be worthwhide. Despite this the volume can be recotionmended as a standard guide to literature. 